\title{
TOP mRNPs: Molecular Mechanisms and Principles of Regulation
}

\author{
Eric Cockman ${ }^{1}$, Paul Anderson ${ }^{2}$ and Pavel Ivanov ${ }^{2, *}$ \\ 1 Brigham and Women's Hospital, Harvard Medical School, Boston, MA 02115, USA; \\ ecockman@bwh.harvard.edu \\ 2 Brigham and Women's Hospital, Harvard Medical School, Harvard Initiative for RNA Medicine, \\ Boston, MA 02115, USA; panderson@bwh.harvard.edu \\ * Correspondence: pivanov@rics.bwh.harvard.edu; Tel.: +1-617-525-1233
}

Received: 21 May 2020; Accepted: 23 June 2020; Published: 27 June 2020

check for updates

\begin{abstract}
The cellular response to changes in the surrounding environment and to stress requires the coregulation of gene networks aiming to conserve energy and resources. This is often achieved by downregulating protein synthesis. The $5^{\prime}$ Terminal OligoPyrimidine ( $5^{\prime}$ TOP) motif-containing mRNAs, which encode proteins that are essential for protein synthesis, are the primary targets of translational control under stress. The TOP motif is a cis-regulatory RNA element that begins directly after the $\mathrm{m} 7 \mathrm{G}$ cap structure and contains the hallmark invariant $5^{\prime}$-cytidine followed by an uninterrupted tract of 4-15 pyrimidines. Regulation of translation via the TOP motif coordinates global protein synthesis with simultaneous co-expression of the protein components required for ribosome biogenesis. In this review, we discuss architecture of TOP mRNA-containing ribonucleoprotein complexes, the principles of their assembly, and the modes of regulation of TOP mRNA translation.
\end{abstract}

Keywords: 5' Terminal Oligopyrimidine; RNA binding proteins; LARP1; translation regulation; RNA

\section{Translation Initiation and Regulation}

The $5^{\prime} 7$-methylguanosine (m7G) cap found at the $5^{\prime}$ terminus of most mRNAs plays a major role in the initiation of translation. Its recruitment of eIF4E, a major cap binding protein, is the first step in the assembly of a pre-initiation complex (PIC) that includes eIF4G, eIF4A, eIF3, the eIF2 $\alpha$-GTP-tRNAiMet ternary complex, and the 40S small ribosomal subunit. This 43S PIC scans the $5^{\prime}$ untranslated region until the tRNAiMet anticodon pairs with the AUG start codon (Figure 1, upper panel). This recognition event triggers GTP hydrolysis, release of several initiation factors, and recruitment of the 60S ribosomal subunit to allow translation to begin. The availability of active eIF2 $\alpha$-GTP-tRNAiMet ternary complex is influenced by environmental conditions. Under optimal growth conditions, the GTP-charged "active" ternary complex is abundant and mRNA translation is unimpaired. Under stress conditions (e.g., oxidative stress, viral infections, amino acid starvation, and ER stress), phosphorylation of eIF2 $\alpha$ by one of several stress-activated kinases (e.g., heme-regulated inhibitor kinase (HR1), protein kinase RNA (PKR), general control non-repressible-2 (GCN2), and PKR-like ER Kinase (PERK) [1-4]) inhibits the GDP:GTP exchange reaction, depleting eIF2 $\alpha$-GTP-tRNAiMet, and inhibiting translation initiation [5]. For a more thorough review of translational initiation and how it is regulated, see [6,7].

The mammalian target of rapamycin complex 1 (mTORC1) plays an important role in reprogramming protein synthesis in cells subjected to metabolic stress. This is accomplished by altering the structure of the translation initiation complex to modulate the efficiency of protein synthesis. Under growth conditions, active mTORC1 phosphorylates the eIF4E Binding Proteins (4E-BPs), to prevent their interaction with eIF4E (Figure 1, upper panel). This allows eIF4E to complex with eIF4G and eIF4A to assemble initiation complexes that support protein synthesis. Under starvation 
conditions, inactivation of mTORC1 results in a lack of phosphorylation of 4E-BP. Unphosphorylated $4 \mathrm{E}-\mathrm{BP}$ binds to eIF4E, displacing eIF4G, and inhibiting protein synthesis [8]. Thus, phosphorylation of eIF2 $\alpha$ and dephosphorylation of $4 \mathrm{E}-\mathrm{BP}$ play important roles in reprogramming protein synthesis during stress.

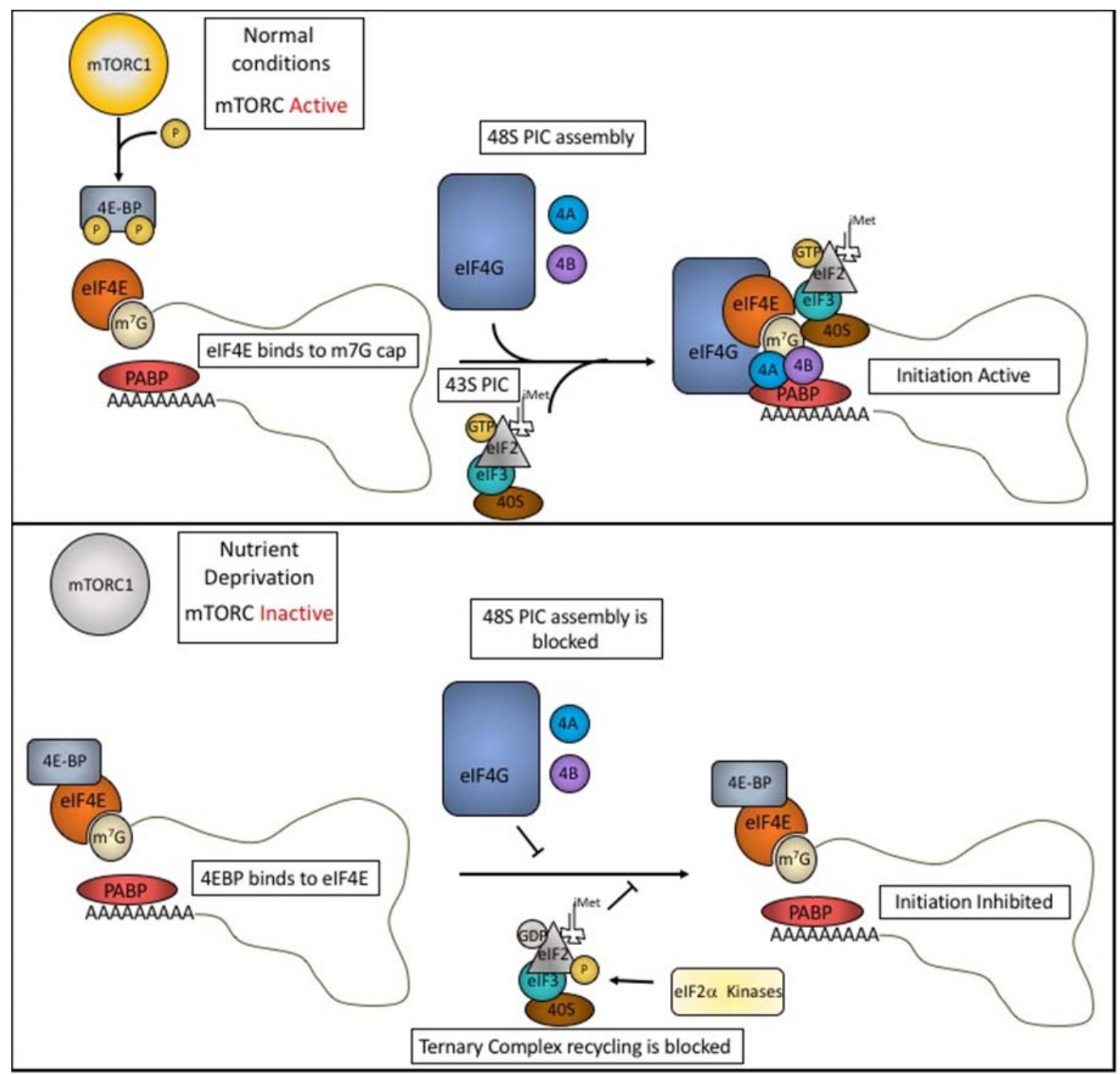

Figure 1. Cap-dependent translation initiation and regulation. Upper panel: Under normal conditions, mTORC1 phosphorylates and inactivates $4 \mathrm{E}-\mathrm{BPs}$. eIF4E binds to the $\mathrm{m} 7 \mathrm{G}$ cap of the transcript and recruits eIF4G, eIF4A (4A), and eIF4B (4B) forming the eIF4F cap binding complex. eIF4F recruits the 435 pre-initiation complex (PIC) consisting of eIF3, the ternary complex (eIF2, GTP, and the initiator Methionine tRNA), and the $40 \mathrm{~S}$ small ribosomal subunit to form the $48 \mathrm{~S}$ PIC. Lower Panel: During nutrient deprivation, mTORC1 is inactivated resulting in hypo-phosphorylated 4E-BP. 4E-BP can then bind to eIF4E and block assembly of eIF4F, in turn, halting translation initiation. The eIF $2 \alpha$ kinases are activated during stress responses and phosphorylate eIF2 $\alpha$. This phosphorylation interferes with GDP exchange and renders the ternary complex inactive.

\section{The 5' TOP Motif}

Protein synthesis is an essential function that requires an abundant investment of both energy and resources from cells. A myriad of ribosomal proteins, initiation, and elongation factors are necessary for translation to support cell growth and proliferation. Under normal conditions, ribosomes and translation factors are synthesized in coordination with cellular demands. However, under adverse conditions, such as amino acid deprivation or hypoxia, translation is halted, and the energy and resources required to support protein synthesis are redirected to resolve stress-induced cellular damage. 
mRNAs encoding proteins require for translation are distinguished by a $5^{\prime}$ Terminal OligoPyrimidine (5' TOP) motif. The $5^{\prime}$ TOP motif begins with a $\mathrm{m}^{7} \mathrm{G}$ capped $\mathrm{C}$ nucleotide followed by a run of approximately 4-15 pyrimidines [9] often followed by a G-rich region [10,11] (Table A1). The 5' TOP motif is highly conserved and is found in all 79 human ribosomal proteins as well as non-ribosomal proteins involved in translation including multiple subunits of eIF3, eIF4A, eEF2, and poly(A) binding protein (PABP) [12]. This shared TOP motif allows cells to quickly modulate the expression of proteins involved in ribosome production and protein synthesis in response to changes in cellular homeostasis.

\section{Regulation of TOP mRNAs}

The expression of proteins encoded by TOP mRNAs is sensitive to the cellular energy state. When amino acid or oxygen levels are depleted, translation of TOP mRNAs is decreased [13,14]. Translation of TOP mRNAs can be stimulated by replenishment of growth factors and nutrients through the closely integrated $\mathrm{mTORC} 1$ and PI3K pathways. Several studies have demonstrated the importance of the mTORC1 signaling pathway on the regulation of TOP mRNAs. Disruption of mTORC1 signaling using inhibitors, such as rapamycin and Torin1 [15], leads to a marked decrease in translation of transcripts containing the $5^{\prime}$ TOP motif [16]. By employing ribosome profiling techniques, Thoreen et al. were able to study the translational rate of RNA transcripts in mouse cells treated with Torin1 [17]. This study aimed to identify the classes of transcripts that are regulated by mTORC1 and found that translational regulation of TOP transcripts was affected when mTORC1 signaling was disrupted [17]. The 4E-BP proteins downstream of mTORC1 were shown to play a role in the decrease of TOP protein synthesis when mTORC1 was inhibited [17]. Knockout of 4E-BP allowed TOP mRNAs to be 'immune' to repression by the mTORC1 inhibitor, Torin1. However, Miloslavski et al. later showed that 4E-BPs did not have a role in regulation of TOP transcript translation during physiological stresses such as oxygen deprivation and nutrient starvation [14]. Rather, Miloslavski suggests that the TOP transcript regulation during oxygen deprivation could be through an mTORC1-independent pathway and that the reliance on 4E-BP seen by Thoreen et al. can be attributed to a property of the cultured cell line used.

More recent studies using compound screens have shown that TOP mRNA translation can also be regulated by mTORC1/4E-BP-independent pathways $[17,18]$. One such pathway was through the eIF2 $\alpha$ kinase, GCN2. These findings point to a more complex regulatory circuitry for TOP transcripts. While early studies suggested that TOP translation can be regulated through mTORC1 or other nutrient sensing pathways $[13,14]$, there has long been evidence of more direct means of regulation. In vitro competition studies using 'TOP-like' synthetic RNA oligos revealed the existence of a trans-acting factor that could regulate the translation of TOP transcripts. A great deal of effort has been put into the identification and functional characterization of proteins that bind to the $5^{\prime}$ TOP motif. This review focuses on the role of $5^{\prime}$ TOP motif-binding proteins and their roles in the control and regulation of $5^{\prime}$ TOP mRNA translation.

It should be noted that 'TOP-like' motifs consisting of oligopyrimidine tracts found internally within a $5^{\prime}$ untranslated region (UTR) have been reported to be regulated by $\mathrm{mTORC} 1$ in a manner similar to TOP transcripts [17]. However, early work on 5' TOP motifs by Avni et al. showed that moving the TOP motif away from the $5^{\prime}$ terminus of the mRNA transcript decouples it from metabolic regulation [10]. Furthermore, as will be discussed later in the review, the binding of the major TOP regulatory protein requires the presence of a $\mathrm{m}^{7} \mathrm{G}$ cap that would be absent from $5^{\prime}$ UTR internal, TOP-like motifs. Thus, regulation of TOP-like motifs may be occurring through different mechanisms than those that control 5' TOP motifs.

\section{The La Family of Proteins}

One of the most widely studied families of RNA binding proteins (RBPs) is the La family [19]. La is a conserved RNA binding protein that is primarily nuclear. The ability of La proteins to bind to RNA is conferred by the La Module, a unique combination of a La motif (LaM) connected to an RNA Recognition Motif (RRM) [20-23] (Figure 2). The La Module is found in the La protein as well as in the 
La-related proteins (LARPs) [24,25]. RNA substrates for the different La family members can differ due to variations within the La Module [25]. La plays a key role in the biogenesis and maturation of RNA Polymerase III transcripts. During tRNA maturation, La binds to pre-mature tRNA through interactions with the 3' UUU-OH feature found in RNA polymerase III transcripts [26-28]. Once bound to a pre-tRNA, La increases structural stability [29], protects from premature degradation [30], and acts as a chaperone during modification and splicing events [31,32].

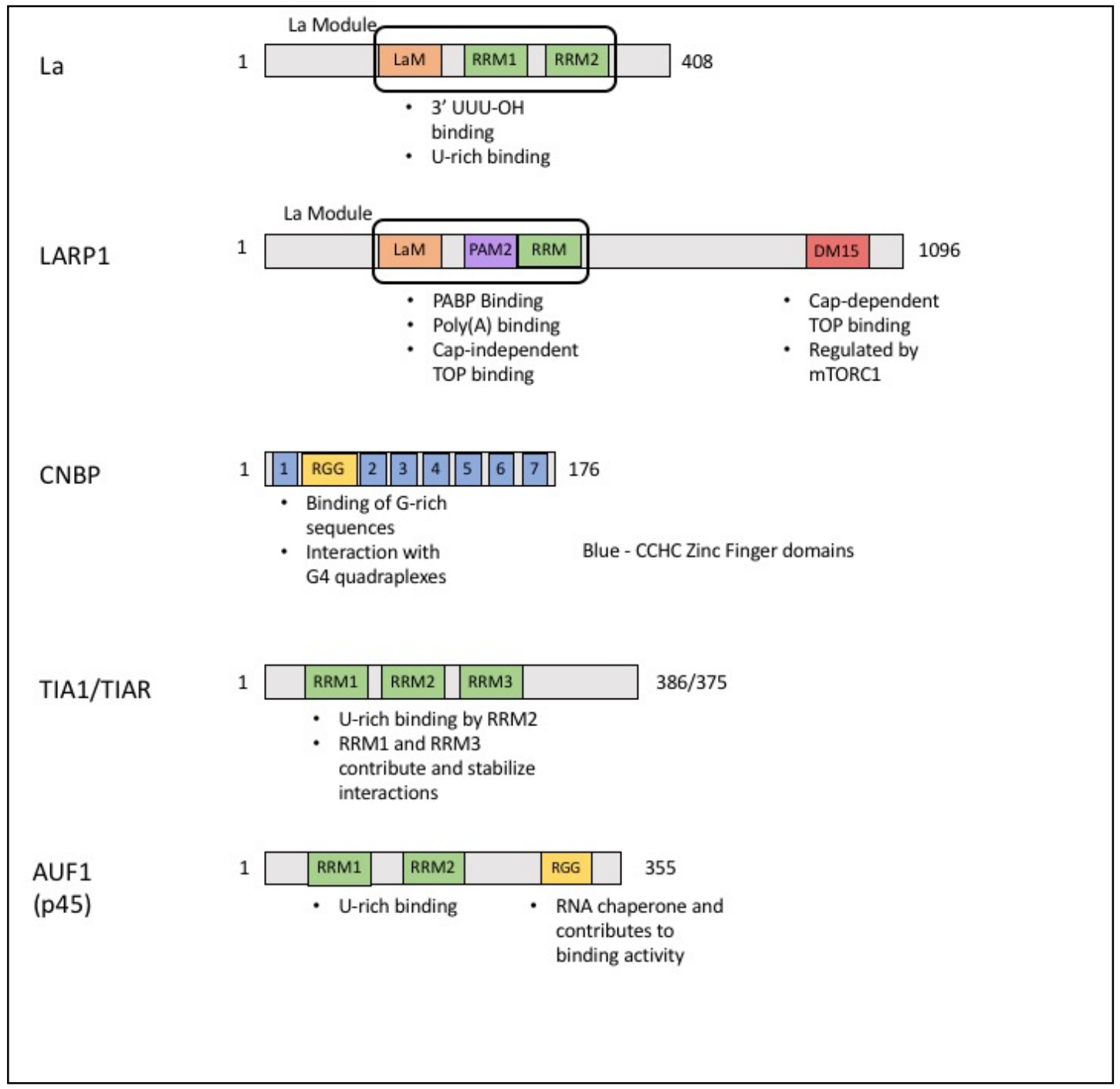

Figure 2. Schematics of 5' TOP motif binding proteins and their RNA binding domains. La possesses the La Module consisting of the La Motif (LaM, orange) as well as two RNA recognition motifs (RRM, green). LARP1 also has the La module but with a poly(A) binding protein (PABP)-interacting motif (PAM2, purple). There is also the DM15 (red) domain in the C-terminal region that is required for 5' TOP motif and cap binding. Cellular Nucleic Acid Binding Protein (CNBP) contains seven CCHC-zinc finger repeats (1-7, blue) as well as an arginine/glycine rich motif (RGG, yellow). AUF1 has four isoforms, p45 is the chosen canonical isoform shown here. AUF1 contains two RRMs as well as an RGG motif. All four isoforms contain the RRMs. In p42 and p45, the RGG is interrupted by an alternatively spliced exon.

La was first shown to associate with 5' TOP mRNAs in Xenopus laevis [33]. Due to the affinity of La protein for 3' UUU-OH motifs in associated transcripts, this interaction is likely mediated by interactions with oligo $U$ tracts within the 5' TOP motif. La was shown to bind to 5' TOP motifs and stimulate translation in both Xenopus laevis and human cell lines [34]. In these studies, binding of 
La to TOP transcripts was found to be greater in growing Xenopus laevis cells than in resting cells. Interestingly, over-expression of La in resting cells led to an increase in TOP mRNA translation [34]. In further support of a stimulatory role, La was shown to associate with TOP transcripts during translation in vivo [35]. In contrast, other groups have reported that increasing amounts of non-phosphorylated La correlates with decreased translation of TOP mRNAs [36-38]. It has also been reported that La has no effect on TOP mRNA translation based on knockout and over-expression experiments [39]. Due to these conflicting results, the role of La in the translational regulation of TOP transcripts remains uncertain [11].

\section{La Related Protein 1 (LARP1)}

\subsection{LARP1 Binds 5' TOP Motifs in a Sequence Dependent Manner}

While the La protein does not appear to play a direct role in $5^{\prime}$ TOP mRNA regulation, the closely related protein, La related protein 1 (LARP1), is a prime candidate for being a core regulator of TOP translation. Like La, LARP1 is a nuclear and cytosolic RNA-binding protein that contains a La module consisting of a LaM and RRM [40]. First identified as a protein that binds to TOP transcripts in Xenopus laevis [36,37], LARP1 binds to the 5' TOP motif through its C-terminal DM15 domain [41]. Interestingly, binding of $5^{\prime}$ TOP motifs was shown to be independent of the La module [41]. The DM15 domain is a highly conserved combination of three HEAT-like helix-turn-helix regions. More complex studies using crystal structures of the human LARP1 DM15 region revealed that Lys-915 stabilizes the $\gamma$-phosphate of the $\mathrm{m}^{7} \mathrm{G}$ cap and the $\mathrm{C} 1$ nucleotide of the TOP motif interacts with Arg- 879 and Arg-847 in the helix-turn-helix region [42]. See [42] for a detailed structural analysis of LARP1 and TOP motif interactions. These coordinating residues are conserved throughout worm, plants, and mammals. Using RNA electromobility shift assays (REMSA), Lahr et al. showed that binding of DM15 to RNA required both the $\mathrm{m}^{7} \mathrm{G}$ cap and the $\mathrm{C} 1$ nucleotide of the $5^{\prime} \mathrm{TOP}$ motif. When the $\mathrm{m}^{7} \mathrm{G}$ cap was removed or C1 was mutated to G, DM15 binding affinity was decreased by approximately 90-fold [42]. This detail of DM15 binding poses an interesting challenge for studying LARP1. Commercially available RNA polymerases, using SP6 or T7 promoters, can only produce RNA transcripts beginning with guanine. To overcome this obstacle, several clever biochemical approaches have been employed. Production of short, chemically synthetized TOP motifs have been used to study binding dynamics of LARP1 [16,41,42]. A system utilizing cleavage by hammerhead ribozymes followed by splint ligation of a 5' TOP oligo has also been used successfully to study the biological role a 5' TOP motif has on translation $[16,42]$.

\subsection{LARP1 Represses Translation of TOP Transcripts}

Early work in Drosophila identified LARP1 as a PABP binding partner that is an important player in cell proliferation and fertility [43]. It was also shown that depletion of LARP1 in the Human Embryonic Kidney cell line, HEK293 leads to a reduction in proliferation [16]. LARP1 has also been identified as a strongly expressed protein in several malignant cancers that correlates with progression and poor outcome [44-47]. The role of LARP1 on TOP RNA regulation was first reported based on its observed effect on RNA stability. Using RNA immunoprecipitation and proteomics, Aoki et al. identified LARP1 as a protein that binds to poly(A) tails of RNA transcripts [48]. They further showed that LARP1 was able to increase the steady state levels of mature TOP transcripts and concluded that LARP1 was a promoter of TOP protein expression [48]. To further support this, it has been shown that LARP1 can interact with the 40S ribosomal subunit and selectively stabilize TOP transcripts [49]. It has also been reported that LARP1 associates with translating ribosomes through interactions with PABP and is able to promote translation of mRNAs containing $5^{\prime}$ TOP motifs [40]. In contrast, Fonseca et al. reported LARP1 as a repressor for TOP translation that is regulated by mTORC1. In this study, LARP1 was able to compete with eIF4G binding to capped TOP transcripts and inhibit translation [13]. Fonseca suggests that the apparent discrepancy between these observations may be due a decrease in 
cell viability and protein synthesis when LARP1 is robustly knocked down [13]. Moderate LARP1 knockdown, as used in Fonseca's study, resulted in less disruption of overall translation rates and allowed for the identification of an inhibitory effect. Several other groups have since reported the inhibitory effect of LARP1 on TOP translation [16,40,42].

\subsection{LARP1 Binding and TOP Repression Is Controlled by mTORC1 Signaling}

As TOP mRNA translation is strongly regulated by the mTORC1 pathway, it comes as no surprise that LARP1 is also a target of mTORC1 signaling. Using a proteomic approach, Fonseca et al. showed that LARP1 interacts with mTORC1 not only functionally, but also physically. It was further shown that this interaction was mediated by the regulatory-associated protein of mTOR (RAPTOR) [13]. This interaction with mTORC1 is important for LARP1's ability to bind to TOP mRNAs. When mTORC1 was inactivated using rapamycin or Torin1, LARP1 interaction with TOP mRNAs was increased as measured by RNA immunoprecipitation. This increase in LARP1 binding was accompanied by a decrease of eIF4G interaction with TOP transcripts. Furthermore, when LARP1 was knocked down in HEK293T cells, inhibition of TOP translation by pharmacological agents was rescued. Phospho-proteomic studies have revealed several residues in LARP1 that are phosphorylated by mTORC1 [50-52]. Phosphorylation of two residues, Ser-744 and Ser-766, was shown to be inhibited by rapamycin and Torin1 [53]. Interestingly, these two residues are found near the DM15 region of LARP1 [41]. Philippe et al. showed that DM15 domain of LARP1 was necessary and sufficient for repression of TOP RNAs in both cells and in vitro systems, and also showed that this repression was responsive to mTOR inhibition by Torin1 [16]. Furthermore, it was shown that a region downstream of the DM15 domain allowed for regulation of LARP1 binding to TOP RNAs. This observation further adds evidence to potential mTORC1 phosphorylation sites regulating the interaction between LARP1 and 5' TOP motifs. Intriguingly, it has also been reported that LARP1 stabilizes the mTOR mRNA likely through interactions with its 3' UTR [54]. The possibility of a feedback loop between LARP1 and the mTOR pathway could lead to novel insights into the complexities of energy states and ribosome biogenesis.

\subsection{LARP1 Inhibits Translation of TOP Transcripts by Competing with Initiation Factors}

LARP1 has been shown to be a mTORC1 regulated protein that binds to 5' TOP motifs and controls translation of TOP mRNAs. As previously discussed, canonical, cap-dependent translation requires binding of eIF4E to the cap structure with further recruitment of eIF4G and eIF4A to assemble the eIF4F complex that recruits the ribosome (Figure 1). Competition studies using REMSAs has shown that LARP1 competes with eIF4E for binding to the cap structure of TOP mRNAs [13]. More intriguingly, LARP1 is able to displace eIF4F from TOP RNAs even at sub-stoichiometric levels [42]. As demonstrated in other studies, LARP1 binding is highly dependent upon the nucleotide after the $\mathrm{m}^{7} \mathrm{G}$ cap being a cytosine, a pyrimidine, and binding is greatly diminished when it is replaced by a purine. Analysis of mRNA features for cap binding of eIF4E shows the opposite. eIF4E has a higher affinity for purines (A and $G$ ) over pyrimidines ( $C$ and $U$ ) $[55,56]$. This decreased affinity of eIF4E for $5^{\prime}$ TOP motifs could also explain why increasing 4E-BP expression appears to selectively inhibit TOP translation [17]. Based on this observation, it has been speculated that as 4E-BP levels increase and block the binding of eIF4E to cap structures, the transcripts with lower affinity for eIF4E binding, such as TOP transcripts, may be repressed earlier than transcripts with a higher affinity for eIF4E $[17,57]$.

\subsection{LARP1 Regulation of TOP Transcripts is Complex}

As alluded to earlier, LARP1 also interacts with poly(A) tails of mRNA transcripts as well as with PABP $[40,48,58]$. This observation was further confirmed by Fonseca et al. and shown to be mediated by a PAM2-like domain found in the La module [13]. Deletion and mutation of this region resulted in a decrease in PABP binding by LARP1. It was further shown that the interaction with PABP was independent of RNA and mTORC1 regulation [13]. Recent work has revealed that LARP1 can also interact with the poly(A) tail through its La Module [58]. Here, Al-Ashtal et al. suggest a model in 
which LARP1 interacts with TOP transcripts in both nutrient rich and nutrient starved conditions through interactions with the La module. This observation may reconcile the apparent contradiction between descriptions of LARP1's role in translation regulation. When mTORC1 is inactivated during nutrient deprivation, the DM15 domain of LARP1 is able to 'clamp' onto the 5' cap of the TOP transcript. Fonseca et al. showed that inactivation of mTORC1 due to nutrient deprivation leads to an activation of LARP1 by hypophosphorylation [13]. The DM15 region of LARP1 then binds to the $5^{\prime}$ TOP motif and inhibits assembly of the eIF4G initiation complex thereby halting translation (Figure 3, upper panel). Together these data support a role for LARP1 in directly binding and controlling the fate of TOP mRNA translation. This regulation appears to be complex and can be tuned depending on the energy status of the cell.

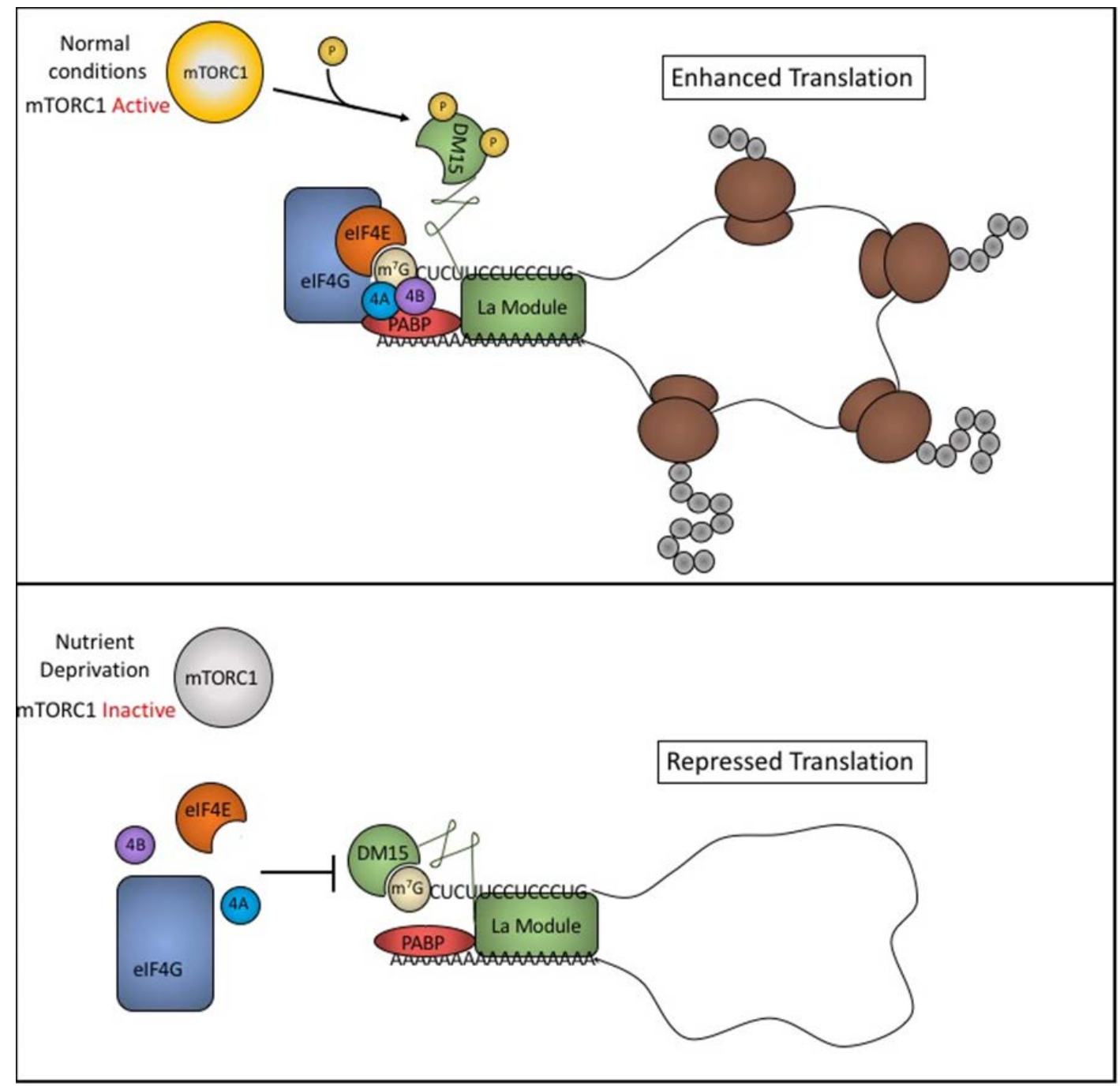

Figure 3. LARP1 regulates translation of $5^{\prime}$ TOP motif containing transcripts. Upper panel: Under normal nutrient conditions, the DM15 domain of LARP1 is unable to bind to the M7G cap allowing eIF4E binding, eIF4F assembly, and procession of translation initiation. The La module of LARP1 binds to the poly(A) tail, PABP, and the $5^{\prime}$ TOP motif in a cap independent manner. These interactions promote circularization of the TOP transcript and enhance translation. Lower panel: Nutrient deprivation leads to inactivation of mTORC1 and hypophosphorylation of residues in or near the DM15 domain allowing it to bind to the 5' TOP motif and the m7G cap. DM15 blocks interactions of eIF4E with the cap and halts the downstream steps required for cap-dependent translation initiation thereby repressing translation. 


\section{Cellular Nucleic Acid Binding Protein (CNBP)}

Cellular Nucleic Acid Binding Protein (CNBP) is a DNA and RNA binding protein that has been shown to bind to G-rich regions of 5' TOP containing transcripts in both Xenopus laevis and humans [33,59,60]. Since its discovery, it has been implicated in the development of Myotonic dystrophy type 2 (DM2) [61]. DM2 is a multisystemic disease that is characterized by myotonia, muscle weakness, cardiac and endocrinological defects, and changes in cognitive functions [62]. Onset of DM2 is linked to an expansion of rCCTG repeats found in the first intron of CNBP [61]. Normally, this intron includes 11 to 26 CCTG repeats. In DM2 patients, this intron includes between 75 to 11,000 CCTG repeats [61]. These repeats lead to a reduction of CNBP expression that have been confirmed in animal models of DM2 [63] as well as muscle biopsies of DM2 patients [64]. Low levels of CNBP in DM2 patients were linked to a reduction in the expression of ribosomal proteins and other TOP transcript products including PABP and eEF2 [59]. A decrease in the transcripts that are required for protein synthesis leads to a decrease in overall protein production in patient-derived DM2 cell lines [59,65]. When CNBP was expressed in a DM2 myoblast model, TOP mRNA translation was restored $[59,65]$. These observations suggest that CNBP may have a positive role in TOP transcript translation.

Using PAR-CLIP analysis, Benhalevy et al. were able to identify G-rich CNBP binding sites in $\sim 4000$ mRNA transcripts, including TOP transcripts [66]. Many of these G-rich regions have also been shown to form G-quadruplex (G4) structures [67,68]. G4-structures are formed when tracts of guanines in an RNA or DNA interact through Hoogsteen base pairing [69]. The guanine repeats form a four-stranded structure that is highly stable. CNBP binds RNA via seven CCHC-Zinc Finger motifs and an arginine/glycine-rich motif (RGG motif). Benhalevy et al. used ribosome profiling to show that CNBP binding to G-rich regions increases translation. Depletion of CNBP increased the appearance of stalled ribosomes near predicted CNBP-binding sites [66]. Furthermore, CNBP was shown to inhibit the formation of G4 structures in a dose-dependent manner. These findings suggest that G4 structures inhibit ribosome elongation and that CNBP promotes translation by binding to and resolving G4 structures.

While there is compelling evidence that CNBP binds downstream of $5^{\prime}$ TOP motifs and can potentially promote their translation, evidence that CNBP directly modulates the translation of TOP transcripts is lacking. In contrast, there is strong evidence that LARP1 represses the translation of TOP transcripts. It is nevertheless possible that both of these proteins contribute to this regulatory process. One attractive model is that LARP1 and CNBP bind to distinct regions of TOP transcripts and have opposing effects on translation (Figure 3). Futures studies clarifying the role of CNBP in the modulation of TOP transcript expression are needed.

\section{T-Cell Intracellular Antigen (TIA1) and TIA-Related Protein (TIAR)}

TIA1 and TIAR are closely related RBPs that share three RRMs and a prion-related carboxy-terminal domain. Sequence similarity between the three RRMs is high $(79 \%, 89 \%$, and $91 \%$, respectively) and RRM2 has a high affinity for U-rich regions [70]. TIA1 and TIAR bind to Adenine/Uridine-rich elements (AREs) in the 3' UTR of mRNA transcripts. AREs are commonly found in transcripts that encode proteins involved in proliferation, stress response, and immune functions [71,72]. When bound to these transcripts, TIA1 and TIAR function as translational repressors [73,74]. TIA1 and TIAR-dependent translational repression is enhanced in cells exposed to environmental stress. Phosphorylation of eIF2 $\alpha$ during stress induces assembly of stalled $48 \mathrm{~S}$ pre-initiation complexes (PIC). TIA1 and TIAR bind to PIC-bound transcripts whereupon their prion-related domains promote condensation into stress granules [75]. Protein and RNA content of stress granules is dynamic and selective based on several factors such as severity and nature of cellular stress and the expression of stress granule-associated proteins [76-78]. With the resolution of stress, stress granule disassembly correlates with the resumption of protein synthesis [79]. 


\section{TIA1 and TIAR in TOP Regulation}

TIA1 and TIAR also bind to $5^{\prime}$ TOP motifs as shown in experiments using Systematic Evolution of Ligands by Exponential enrichment (SELEX) analysis, gene array studies, and RNA immunoprecipitation $[72,80,81]$. This binding is likely due to the U-rich nature of the pyrimidine tracts. Damgaard and Lykke-Anderson showed that amino acid starvation triggers the recruitment of TIA1 and TIAR to $5^{\prime}$ TOP transcripts and inhibits translation. Interestingly, transcripts that have TIA1/TIAR binding sites within their 3' UTR, but not a 5' TOP motif, are exempt from regulation due to amino acid starvation [80]. This study also showed that TOP transcript repression by TIA1 and TIAR is dependent on GCN2 signaling. As mentioned above, stress granule formation depends on phosphorylation of eIF $2 \alpha$ to deplete translationally competent initiation complexes. GCN2 activation induces phosphorylation of eIF2 $\alpha$ and triggers stress granule formation. GCN2 activation and the selective binding of TIA/TIAR to $5^{\prime}$ TOP transcripts work together to repress production of TOP proteins by sequestering their transcripts into stress granules during amino acid starvation. Further studies to determine how TIA1 and TIAR interact with the 5' TOP motif and translation initiation factors need to be performed to completely understand the mechanism of this observation.

\section{ARE/poly(U)-Binding/Degradation Factor 1 (AUF1)}

$\mathrm{ARE} /$ poly(U)-binding/degradation factor 1 (AUF1) is a family of proteins consisting of four isoforms generated by alternative splicing [82]. The four isomers have differing molecular weights (p37, p40, p42, p45) and form stable dimers in both the nucleus and cytoplasm, though not in equal proportions [82]. Each of these isoforms contains two conserved RRMs and an RGG motif (Figure 2). These motifs are necessary for AUF1 to recognize and bind to U-rich regions [83,84]. While the RRMs of AUF1 alone can bind RNA, high affinity interactions require the RRMs as well as the RGG motif found in the C-terminus of the protein [85]. The RNA affinity for each of the AUF1 isoforms are not identical due to the absence of different retained introns [86].

AUF1 functions in both mRNA turnover and translational control. AUF1 binds to AREs in the 3' UTR of transcripts and is thought to recruit other protein factors that facilitate mRNA decay [87]. However, there are also reports of AUF1 binding and stabilizing other transcripts such as IL- 6 and TGF- $\beta$ in breast fibroblast cell lines [88,89]. More recently, AUF1 was shown to stabilize both VEGF-A and HIF1 $\alpha$ by binding to sequences in their $3^{\prime}$ UTRs [90]. Interestingly, AUF1 has been shown to compete with TIAR for binding to MYC transcripts [91]. In this system, TIAR suppresses Myc expression, while binding of AUF1 in place of TIAR supports translation of Myc. However, the role of AUF1 in translational control is not well understood. Ribosome profiling experiments have revealed that AUF1 levels can affect ribosome occupancy on a number of transcripts [92]. The majority of these AUF1-associated transcripts do not undergo changes in steady state mRNA levels. These observations suggest that AUF1 is controlling translation by a mechanism other than mRNA stability or decay.

While AUF1 is primarily associated with transcript stability and translational control, it was also identified as a protein that binds to $5^{\prime}$ TOP motifs in an mTOR dependent manner [93]. Using modified tandem column chromatography, Kakegawa et al. were able to isolate and identify two protein that bound to the $5^{\prime}$ TOP motif of RPL32 in vitro. Further analysis identified these proteins as the p42 and p45 isoforms of AUF1. Levels of p42 and p45 AUF1 were decreased in polysome fractions when $B J A B$ cells, a malignant human B-cell line, were treated with rapamycin to inhibit translation of TOP transcripts. This result suggests that AUF1 may have a stimulatory effect on TOP translation. Unfortunately, the role of AUF1 in TOP translation has not been widely studied. As such, direct evidence for AUF1 binding to TOP transcripts and regulating their expression has yet to be shown. As mentioned above, there is precedent for competition of AUF1 and TIA1/TIAR for common binding sites [91]. Competitive binding between these proteins may be a regulatory point for the translation of TOP transcripts (Figure 4). 


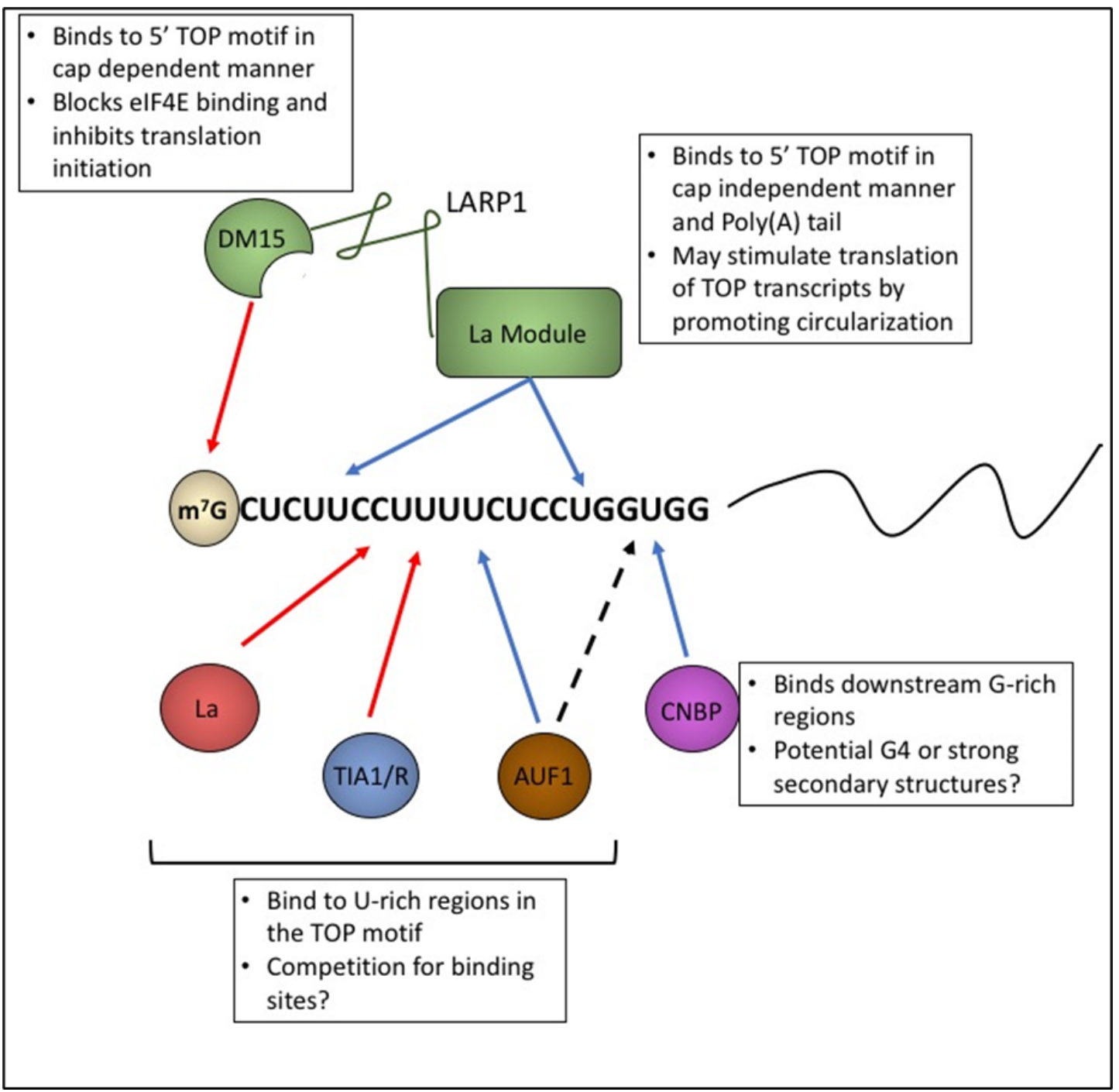

Figure 4. Multiple proteins bind to 5' TOP motifs and affect translation. Schematic depicting potential interactions of RNPs with the 5' TOP motif. Red arrows depict inhibition of expression and blue arrows depict promoting effects on expression. Different part of LARP1 (green) can interact with the TOP motif and can both promote or repress translation depending on the context. La (red) and TIA1/R (blue) bind to U-rich regions of the TOP motif and are thought to play an inhibitory role in TOP expression. AUF1 (brown) also binds to U-rich regions of the TOP motif but appears to have a promoting effect on expression. Furthermore, La, TIA1/R, and AUF1 may compete for binding sites. CNBP interacts with G-rich regions near the distal part of the TOP motif. CNBP as well as AUF1 may associate with secondary structures and potential G4 quadraplexes that may form in this region of some TOP motifs through their RGG motifs.

\section{Conclusions}

Expression of ribosomal proteins and other factors required for protein synthesis is key for cellular function. Because protein synthesis is an energy intensive process, a gatekeeper that ensures that energy conditions are sufficient to initiate this program is essential. The 5' TOP motif found in transcripts encoding all human ribosomal proteins, as well as a host of initiation factors, elongation factors, and other proteins required for translation is a good candidate for such a gatekeeper. In this review, the proteins that bind to $5^{\prime}$ TOP motifs and their activities have been discussed. While our understanding of the individual roles each of the binding proteins plays on TOP transcripts is growing, we are still uncovering the complexities of how these proteins are regulated and the downstream consequences 
of that regulation on protein synthesis. Furthermore, how these proteins interact with each other in the context of binding and regulating expression of TOP transcripts has yet to be elucidated. LARP1, CNBP, AUF1, and TIAR/1 have all been reported to be in stress granules [75,94-96]. Colocalization within stress granules may provide opportunity for these proteins to interact. Moving forward, studies highlighting the potential for interplay between different TOP binding proteins and their associated regulatory pathways will lead to a greater understanding of how protein synthesis and ribosome production are modulated during stress events in cells.

Author Contributions: Conceptualization, P.I. and E.C.; writing-original draft preparation, E.C.; writing-review and editing, P.I., P.A.; supervision, P.I.; project administration, P.I.; funding acquisition, P.I., P.A. All authors have read and agreed to the published version of the manuscript.

Funding: This work was supported by the National Institutes of Health [R35 GM126901 to P.A., RO1 GM126150 to P.I.].

Acknowledgments: We thank members of Ivanov and Anderson labs for discussion and helpful critique.

Conflicts of Interest: The authors declare no conflict of interest.

\section{Appendix A}

Table A1. List of transcripts containing 5' TOP motifs. The first 50 nucleotides of each TOP transcript. The $5^{\prime}$ TOP motif is highlighted in yellow and guanines are in red.

\begin{tabular}{|c|c|c|}
\hline Gene & 5' UTR (First 50 Nucleotides) & Accession No. \\
\hline RPSA & CUUUUUCC GUGCUACCUGCAGAGGGGUCCAUACGGCGUUGUUCUGGAUUC & D28372.1 \\
\hline RPS2 & CUUCUUUUCC GACAAAACACCAAAUGGCG & AB055772.1 \\
\hline RPS3 & CCUUUCCUUUC AGCGGAGCGCGGCGGCAAGAUGGCA & D28344.1 \\
\hline RPS3A & CCUUUU GGCUCUCUGACCAGCACCAUGGCG & D28374.1 \\
\hline RPS4X & CUCUUUCCUU GCCUAACGCAGCCAUGGCU & D28359.1 \\
\hline RPS4Y & CUCUUCC GUCGCAGAGUUUCGCCAUGGCC & AB055773.1 \\
\hline RPS5 & CUCUUCCU GUCUGUACCAGGGCGGCGCGUGGUCUACGCCGAGUGACAGAG & D28455.1 \\
\hline RPS6 & CUCUUUUCC GUGGCGCCUCGGAGGCGUUCAGCUGCUUCAAGAUGAAG & D28348.1 \\
\hline RPS7 & CUCUUCCU AAGCCGGCGCUCGGCAAGUUCUCCCAGGAGAAAGCCAUGUUC & АВ055774.1 \\
\hline RPS8 & CUCUUUCC AGCCAGCGCCGAGCGAUGGGC & D28361.1 \\
\hline RPS9 & CUCUUUCUC AGUGACCGGGUGGUUUGCUUAGGUGAGGUGCGG & AB061839.1 \\
\hline RPS10 & CUUUUCC AGCCCCGGUACCGGACCCUGCAGCCGCAGAGAUGUUG & D28427.1 \\
\hline RPS11 & CUUUUUUUUUUUC AGGCGGCCGGGAAGAUGGCG & D28407.1 \\
\hline RPS12 & CUUUCCC UGCCGCCGCCGAGUCGCGCGGAGGCGGAGGCUUGGGUGCGUUC & D28378.1 \\
\hline RPS13 & CCUUUC GUUGCCUGAUCGCCGCCAUCAUGGGU & D28429.1 \\
\hline RPS14 & CUUUUUCC GGUGUGGAGUCUGGAGACGACGUGCAGAAAUGGCA & D28352.1 \\
\hline RPS15 & CUUCU GAGGAUCCGGCAAGAUGGCA & AB055776.1 \\
\hline RPS15A & CUCUUUCC GCCAUCUUUCCGCGCCGCCACAAUGGUG & D28347.1 \\
\hline RPS16 & CUUUUCC GGUUGCGGCGCCGCGCGGUGAGGUUGUCUAGUCCACGCUCGGA & D28392.1 \\
\hline RPS17 & CUCUUUU ACCAAGGACCCGCCAACAUGGGC & AB055777.1 \\
\hline RPS18 & CUCUUCC ACAGGAGGCCUACACGCCGCCGCUUGUGCUGCAGCCAUGUCU & AB055778.1 \\
\hline RPS19 & CUUUCCCCU GGCUGGCAGCGCGGAGGCCGCACGAUGCCU & D28389.1 \\
\hline RPS20 & CUUUUUUUUU GAGGAAGACGCGGUCGUAAGGGCUGAGGAUUUUUGGUCCG & D28358.1 \\
\hline RPS21 & CUUUUCUCUCUC GCGCGCGGUGUGGUGGCAGCAGGCGCAGCCAGCCUCGA & D28422.1 \\
\hline RPS23 & CUCUUUC GCUCAGGCCCGUGGCGCCGACAGGAUGGGC & D28396.1 \\
\hline RPS24 & CUCUUUUCCUCCUU GGCUGUCUGAAGAUAGAUCGCCAUCAUGAAC & D28424.1 \\
\hline RPS25 & CUUCCUUUUU GUCCGACAUCUUGACGAGGCUGCGGUGUCUGCUGCUAUUC & D28369.1 \\
\hline RPS26 & CUCCUCUCUCC GGUCCGUGCCUCCAAGAUGACA & AB056456.1 \\
\hline RPS27 & CUUUCC GGCGGUGACGACCUACGCACACGAGAACAUGCCU & D28454.1 \\
\hline RPS27A & CUUCCUUUUC GAUCCGCCAUCUGCGGUGGAGCCGCCACCAAAAUGCAG & D28404.1 \\
\hline RPS28 & CUCUCC GCCAGACCGCCGCCGCGCCGCCAUCAUGGAC & AB055779.1 \\
\hline RPS29 & CCUUUU ACCUCGUUGCACUGCUGAGAGCAAGAUGGGU & АВ055780.1 \\
\hline
\end{tabular}


Table A1. Cont.

\begin{tabular}{|c|c|c|}
\hline Gene & 5' UTR (First 50 Nucleotides) & Accession No. \\
\hline RPS30 & CUCUUUCUC GACUCCAUCUUCGCGGUAGCUGGGACCGCCGUUCAGUCGCC & D28403.1 \\
\hline RPPO & CUCUC GCCAGGCGUCCUCGUGGAAGUGACAUCGUCUUUAAACCCUGCGUG & D28418.1 \\
\hline RPP1 & CUUUUUUUCCU CAGCUGCCGCCAAGGUGCUCGGUCCUUCCGAGGAAGCUA & D28366.1 \\
\hline$R P P 2$ & CCUUUUCCUCCCU GUCGCCACCGAGGUCGCACGCGUGAGACUUCUCCGCC & D28411.1 \\
\hline RPL3 & CUCU ACCGGCGGGAUUUGAUGGCGUGAUGUCU & D28415.1 \\
\hline RPL4 & CUUUUCCU GUGGCAGCAGCCGGGCUGAGAGGAGCGUGGCUGUCUCCUCUC & D23660.1 \\
\hline RPL5 & CUUUUCCC ACCCCCUAGCGCCGCUGGGCCUGCAGGUCUCUGUCGAGCAGC & АВ055762.1 \\
\hline RPL6 & CUUUCUUUCCC AUCUUGCAAGAUGGCG & D28388.1 \\
\hline RPL7 & CUCUUUUUCC GGCUGGAACCAUGGAG & АВ055763.1 \\
\hline RPL7A & CUCUCUCCUCCC GCCGCCCAAGAUGCCG & D28405.1 \\
\hline RPL8 & CUCUUUC GGCCGCGCUGGUGAACAGGACCCGUCGCCAUGGGC & D28421.1 \\
\hline RPL9 & CUUUUUUU GCUGCGUCUACUGCGAGAAUGAAG & D28399.1 \\
\hline RPL10 & CUCUUUCCCUUC GGUGUGCCACUGAAGAUCCUGGUGUCGCCAUGGGC & D28410.1 \\
\hline RPL11 & CUCUUCCU GCUCUCCAUC & NM_000975.5 \\
\hline RPL10A & CUCUUUUCC GGUUAGCGCGGCGUGAGAAGCCAUGAGC & AB055764.1 \\
\hline RPL12 & CUCUC GGCUUUCGGCUCGGAGGAGGCCAAGGUGCAACUUCCUUCGGUCGU & D28443.1 \\
\hline RPL13 & CUUUCC GCUCGGCUGUUUUCCUGCGCAGGAGCCGCAGGGCCGUAGGCAGC & NM_000977.4 \\
\hline RPL13A & CUUUUCC AAGCGGCUGCCGAAGAUGGCG & D28409.1 \\
\hline RPL14 & CUUCUUCCUUCUC GCCUAACGCUGCCAACAUGGUG & АВ055765.1 \\
\hline RPL15 & CCUUUCC GUCUGGCGGCAGCAUCAGGUAAGCCAAGAUGGGU & D28417.1 \\
\hline RPL17 & CUCUUUCCCU AAGCAGCCUGAGGUGAUCUGUGAAAAUGGUU & D28373.1 \\
\hline RPL18 & CUUUCC GGACCUGGCCGAGCAGGAGGCGCAAUCAUGGGA & D28461.1 \\
\hline RPL18A & CUUUU GCGGGUGGCGGCGAACGCGGAGAGCACGCCAUGAAG & D28393.1 \\
\hline RPL19 & CUUUCCUUUC GCUGCUGCGGCCGCAGCCAUGAGU & АB055766.1 \\
\hline RPL21 & CCUUUC GGCCGGAACCGCCAUCUUCCAGUAAUUCGCCAAA & D28406.1 \\
\hline RPL22 & CUUUUUUUUUUCU AACUCCGCUGCCGCC & D28346.1 \\
\hline RPL23 & CCUUUUUUCUUUUUUCC GGCGUUCAAG & D28349.1 \\
\hline RPL23A & CCUUUUC ACAAG & D28401.1 \\
\hline RPL24 & CUUUUCUUUC GCCAUCUUUUGUCUUUCCGUGGAGCUGUCGCC & D28400.1 \\
\hline RPL26 & CUCUUCCCUUUU GCGGCCAUCACCGAAGCGGGAGCGCCAAA & D28413.1 \\
\hline RPL27 & CCUUUUU GCUGUAGGCCCGGGUGGUUGCUGCCGAA & D28453.1 \\
\hline RPL27A & CUUUUUC GUCUGGGCUGCCAAC & АВ055767.1 \\
\hline RPL30 & CUUUUCUC GUUCCCCGGCCAUCUUAGCGGCUGCUGUUGGUUGGGGGCCGU & D28438.1 \\
\hline RPL31 & CUUCCUUUCC AACUUAGACGCUGCAGA & D28386.1 \\
\hline RPL32 & CUUCCUC GGCGCUGCCUACGGAGGUGGCAGCCAUCUCCUUCUCGGCAUCA & D28385.1 \\
\hline RPL34 & CUUCCUCUUCC GGGGACGUUGUCUGCAGGCACUCAGAAUGGUC & D28420.1 \\
\hline RPL35 & CUCUUUCCCUC GGAGCGGGCGGCGGCGUUGGCGGCUUGUGCAGCAAUGGC & D28448.1 \\
\hline RPL36 & CUUU GCGCCACGGCCGUCUCUGGAGAGCAGCAGCCAUGGCC & АВ055769.1 \\
\hline RPL36A & CUUUUUCC GCGCCGAUAGCGCUCACGCAAGCAUGGUU & D28414.1 \\
\hline RPL37 & CUUUCU GGUCUCGGCCGCAGAAGCGAGAUGACG & АВ055770.1 \\
\hline RPL39 & CUUCC GCCAGCUUCCCUCCUCUUCCUUUCUCCGCCAUCGUGGUGUGUUCU & D28397.1 \\
\hline RPL40 & CUUCUUUUUCUUC AGCGAGGCGGCCGAGCUGGUUGGUGGCGGCGGUCGUG & NM_001321022 \\
\hline RPL41 & CUCUC GGCCUUAGCGCCAUUUUUUUGGAAACCUCUGCGCCAUGAGA & D28462.1 \\
\hline eIF3A & CUCCUUCCUUUCC GUCUCUGGCCGGCUGGGCGCGGGCGACUGCUGGCGAG & JX312508.1 \\
\hline eIF3E & CUUUUCUUU GGCAAGAUGGCGGAGUACGACUUGACUACUCGCAUCGCGCA & NM_001568.3 \\
\hline$e i F 3 F$ & CUUCUUUCUC GACAAGAUGG & NM_003754.3 \\
\hline eIF3H & CUCUUUCUUCCU GUCUGCUUGGAAAGAUG & NM_003756.3 \\
\hline$e I F 4 B$ & CUUUU GCGUUCUCUUUCCCUCUCCCAACAUG & NM_001300821 \\
\hline$e E F 1 A$ & CUUUUUC GCAACGGGUUUGCCGCCAGAACACAGGUGUCGUGAAAACUACC & NM_001402.6 \\
\hline eEF1B2 & CCUUUUUCCUCUCUUC AGCGUGGGGCGCCCACAAUUUGCGCGCUCUCUUU & NM_001959.4 \\
\hline eEF1D & CUCCCUUUC AUCAGUCUUCCCGCGUCCGCCGAUUCCUCCUCCUUGGUCGC & NM_032378.6 \\
\hline$e E F 1 G$ & CCUUUCUUU GCGGAAUCACCAUG & NM_001404.5 \\
\hline$e E F 2$ & CUCUUCC GCCGUCGUCGCCGCCAUCCUCGGCGCGACUCGCUUCUUUCGGU & NM_001961.4 \\
\hline Rack1 & CUCUCUUUC ACUGCAAGGCGGCGGCAGGAGAGGUUGUGGUGCUAGUUUCU & NM_006098.5 \\
\hline PABP & CCCCUUCUCCCC GGCGGUUAGUGCUGAGAGUGCGGAGUGUGUGCUCCGGG & NM_002568.4 \\
\hline$h n R N P A 1$ & CCUUUCU GCCCGUGGACGCCGCCGAAGAAGCAUCGUUAAAGUCUCUCUU & NM_002136.4 \\
\hline Nucleophosmin & CUUUCCCU GGUGUGAUUCCGUCCUGCGCGGUUGUUCUCUGGAGCAGCGUU & NM_002520.6 \\
\hline NAP1L1 & CUUUUUU AGCGCCAUCUGCUCGCGGCGCCGCCUCCUGCUCCUCCCGCUGC & NM_139207.5 \\
\hline TCTP & CUUUUCC GCCCGCUCCCCCCUCCCCCCGAGCGCCGCUCC & NM_00128627 \\
\hline Vimentin & CCUCU GCCACUCUCGCUCCGAGGUCCCCGCGCCAGAGACGCAGCCGCGCU & NM_003380.5 \\
\hline
\end{tabular}




\section{References}

1. Harding, H.P.; Zhang, Y.; Bertolotti, A.; Zeng, H.; Ron, D. Perk Is Essential for Translational Regulation and Cell Survival during the Unfolded Protein Response. Mol. Cell 2000, 5, 897-904. [CrossRef]

2. Lu, L.; Han, A.-P.; Chen, J.-J. Translation Initiation Control by Heme-Regulated Eukaryotic Initiation Factor $2 \alpha$ Kinase in Erythroid Cells under Cytoplasmic Stresses. Mol. Cell. Biol. 2001, 21, 7971-7980. [CrossRef]

3. Srivastava, S.P.; Kumar, K.U.; Kaufman, R.J. Phosphorylation of Eukaryotic Translation Initiation Factor 2 Mediates Apoptosis in Response to Activation of the Double-stranded RNA-dependent Protein Kinase. J. Biol. Chem. 1998, 273, 2416-2423. [CrossRef] [PubMed]

4. Wek, S.A.; Zhu, S.; Wek, R.C. The histidyl-tRNA synthetase-related sequence in the eIF-2 alpha protein kinase GCN2 interacts with tRNA and is required for activation in response to starvation for different amino acids. Mol. Cell. Biol. 1995, 15, 4497-4506. [CrossRef] [PubMed]

5. Wek, R.C. Role of eIF2 $\alpha$ Kinases in Translational Control and Adaptation to Cellular Stress. Cold Spring Harb. Perspect. Biol. 2018, 10, a032870. [CrossRef]

6. Advani, V.M.; Ivanov, P. Translational Control under Stress: Reshaping the Translatome. Bioessays 2019, 41, e1900009. [CrossRef]

7. Tahmasebi, S.; Khoutorsky, A.; Mathews, M.B.; Sonenberg, N. Translation deregulation in human disease. Nat. Rev. Mol. Cell Biol. 2018, 19, 791-807. [CrossRef]

8. Mader, S.; Lee, H.; Pause, A.; Sonenberg, N. The translation initiation factor eIF-4E binds to a common motif shared by the translation factor eIF-4 gamma and the translational repressors 4E-binding proteins. Mol. Cell. Biol. 1995, 15, 4990-4997. [CrossRef]

9. Yoshihama, M.; Uechi, T.; Asakawa, S.; Kawasaki, K.; Kato, S.; Higa, S.; Maeda, N.; Minoshima, S.; Tanaka, T.; Shimizu, N.; et al. The Human Ribosomal Protein Genes: Sequencing and Comparative Analysis of 73 Genes. Genome Res. 2002, 12, 379-390. [CrossRef] [PubMed]

10. Avni, D.; Shama, S.; Loreni, F.; Meyuhas, O. Vertebrate mRNAs with a 5'-terminal pyrimidine tract are candidates for translational repression in quiescent cells: Characterization of the translational cis-regulatory element. Mol. Cell Biol. 1994, 14, 3822-3833. [CrossRef]

11. Meyuhas, O.; Kahan, T. The race to decipher the top secrets of TOP mRNAs. Biochim. Biophys. Bioenerg. 2015, 1849, 801-811. [CrossRef] [PubMed]

12. Iadevaia, V.; Caldarola, S.; Tino, E.; Amaldi, F.; Loreni, F. All translation elongation factors and the e, f, and $\mathrm{h}$ subunits of translation initiation factor 3 are encoded by $5^{\prime}$-terminal oligopyrimidine (TOP) mRNAs. RNA 2008, 14, 1730-1736. [CrossRef]

13. Fonseca, B.D.; Zakaria, C.; Jia, J.-J.; Graber, T.E.; Svitkin, Y.; Tahmasebi, S.; Healy, D.; Hoang, H.-D.; Jensen, J.M.; Diao, I.T.; et al. La-related Protein 1 (LARP1) Represses Terminal Oligopyrimidine (TOP) mRNA Translation Downstream of mTOR Complex 1 (mTORC1). J. Biol. Chem. 2015, 290, 15996-16020. [CrossRef] [PubMed]

14. Miloslavski, R.; Cohen, E.; Avraham, A.; Iluz, Y.; Hayouka, Z.; Kasir, J.; Mudhasani, R.; Jones, S.N.; Cybulski, N.; Rüegg, M.A.; et al. Oxygen sufficiency controls TOP mRNA translation via the TSC-Rheb-mTOR pathway in a 4E-BP-independent manner. J. Mol. Cell Biol. 2014, 6, 255-266. [CrossRef]

15. Thoreen, C.C.; Sabatini, D.M. Rapamycin inhibits mTORC1, but not completely. Autophagy 2009, 5, 725-726. [CrossRef] [PubMed]

16. Philippe, L.; Vasseur, J.-J.; Debart, F.; Thoreen, C.C. La-related protein 1 (LARP1) repression of TOP mRNA translation is mediated through its cap-binding domain and controlled by an adjacent regulatory region. Nucleic Acids Res. 2018, 46, 1457-1469. [CrossRef]

17. Thoreen, C.C.; Chantranupong, L.; Keys, H.R.; Wang, T.C.; Gray, N.S.; Sabatini, D.M. A unifying model for mTORC1-mediated regulation of mRNA translation. Nature 2012, 485, 109-113. [CrossRef]

18. Li, B.B.; Qian, C.; Gameiro, P.A.; Liu, C.-C.; Jiang, T.; Roberts, T.M.; Struhl, K.; Zhao, J.J. Targeted profiling of RNA translation reveals mTOR-4EBP1/2-independent translation regulation of mRNAs encoding ribosomal proteins. Proc. Natl. Acad. Sci. USA 2018, 115, E9325-E9332. [CrossRef] [PubMed]

19. Maraia, R.J.; Mattijssen, S.; Cruz-Gallardo, I.; Conte, M.R. The La and related RNA-binding proteins (LARPs): Structures, functions, and evolving perspectives. Wiley Interdiscip. Rev. RNA 2017, 8, e1430. [CrossRef] [PubMed] 
20. Kotik-Kogan, O.; Valentine, E.R.; Sanfelice, D.; Conte, M.R.; Curry, S. Structural Analysis Reveals Conformational Plasticity in the Recognition of RNA 3' Ends by the Human La Protein. Structure 2008, 16, 852-862. [CrossRef] [PubMed]

21. Martino, L.; Pennell, S.; Kelly, G.; Bui, T.T.T.; Kotik-Kogan, O.; Smerdon, S.; Drake, A.F.; Curry, S.; Conte, M.R. Analysis of the interaction with the hepatitis $C$ virus mRNA reveals an alternative mode of RNA recognition by the human La protein. Nucleic Acids Res. 2011, 40, 1381-1394. [CrossRef] [PubMed]

22. Merret, R.; Martino, L.; Bousquet-Antonelli, C.; Fneich, S.; Descombin, J.; Élodie, B.; Conte, M.R.; Deragon, J.-M. The association of a La module with the PABP-interacting motif PAM2 is a recurrent evolutionary process that led to the neofunctionalization of La-related proteins. RNA 2012, 19, 36-50. [CrossRef] [PubMed]

23. He, N.; Jahchan, N.S.; Hong, E.; Li, Q.; Bayfield, M.A.; Maraia, R.J.; Luo, K.; Zhou, Q. A La-related protein modulates 7SK snRNP integrity to suppress $\mathrm{P}-\mathrm{TEFb}$-dependent transcriptional elongation and tumorigenesis. Mol. Cell 2008, 29, 588-599. [CrossRef] [PubMed]

24. Alfano, C.; Sanfelice, D.; Babon, J.; Kelly, G.; Jacks, A.; Curry, S.; Conte, M.R.; Babon, J.J. Structural analysis of cooperative RNA binding by the La motif and central RRM domain of human La protein. Nat. Struct. Mol. Biol. 2004, 11, 323-329. [CrossRef]

25. Martino, L.; Pennell, S.; Kelly, G.; Busi, B.; Brown, P.; Atkinson, R.A.; Salisbury, N.J.; Ooi, Z.-H.; See, K.-W.; Smerdon, S.; et al. Synergic interplay of the La motif, RRM1 and the interdomain linker of LARP6 in the recognition of collagen mRNA expands the RNA binding repertoire of the La module. Nucleic Acids Res. 2014, 43, 645-660. [CrossRef]

26. Boelens, W.C.; Palacios, I.; Mattaj, I.W. Nuclear retention of RNA as a mechanism for localization. RNA 1995, 1, 273-283.

27. Huang, Y.; Intine, R.V.; Mozlin, A.; Hasson, S.A.; Maraia, R.J. Mutations in the RNA Polymerase III Subunit Rpc11p That Decrease RNA 3' Cleavage Activity Increase 3'-Terminal Oligo(U) Length and La-Dependent tRNA Processing. Mol. Cell. Biol. 2005, 25, 621-636. [CrossRef]

28. Stefano, J. Purified lupus antigen la recognizes an oligouridylate stretch common to the $3^{\prime}$ termini of RNA polymerase III transcripts. Cell 1984, 36, 145-154. [CrossRef]

29. Copela, L.A.; Chakshusmathi, G.; Sherrer, R.; Wolin, S.L. The La protein functions redundantly with tRNA modification enzymes to ensure tRNA structural stability. RNA 2006, 12, 644-654. [CrossRef]

30. Kadaba, S.; Krueger, A.; Trice, T.; Krecic, A.M.; Hinnebusch, A.G.; Anderson, J.T. Nuclear surveillance, and degradation of hypomodified initiator tRNAMet in S. cerevisiae. Genome Res. 2004, 18, 1227-1240. [CrossRef]

31. Intine, R.V.; Sakulich, A.L.; Koduru, S.B.; Huang, Y.; Pierstorff, E.; Goodier, J.L.; Phan, L.; Maraia, R.J. Control of Transfer RNA Maturation by Phosphorylation of the Human La Antigen on Serine 366. Mol. Cell 2000, 6, 339-348. [CrossRef]

32. Wolin, S.L.; Matera, A.G. The trials and travels of tRNA. Genome Res. 1999, 13, 1-10. [CrossRef] [PubMed]

33. Pellizzoni, L.; Lotti, F.; Maras, B.; Pierandrei-Amaldi, P. Cellular nucleic acid binding protein binds a conserved region of the 5' UTR of Xenopus laevis ribosomal protein mRNAs. J. Mol. Biol. 1997, 267, 264-275. [CrossRef] [PubMed]

34. Crosio, C. La protein has a positive effect on the translation of TOP mRNAs in vivo. Nucleic Acids Res. 2000, 28, 2927-2934. [CrossRef] [PubMed]

35. Cardinali, B.; Carissimi, C.; Gravina, P.; Pierandrei-Amaldi, P. La Protein Is Associated with Terminal Oligopyrimidine mRNAs in Actively Translating Polysomes. J. Biol. Chem. 2003, 278, 35145-35151. [CrossRef]

36. Intine, R.V.; Tenenbaum, S.A.; Sakulich, A.L.; Keene, J.D.; Maraia, R.J. Differential Phosphorylation and Subcellular Localization of La RNPs Associated with Precursor tRNAs and Translation-Related mRNAs. Mol. Cell 2003, 12, 1301-1307. [CrossRef]

37. Schwartz, E.I.; Intine, R.V.; Maraia, R.J. CK2 Is Responsible for Phosphorylation of Human La Protein Serine-366 and Can Modulate rpL37 5'-Terminal Oligopyrimidine mRNA Metabolism. Mol. Cell. Biol. 2004, 24, 9580-9591. [CrossRef]

38. Zhu, J.; Hayakawa, A.; Kakegawa, T.; Kaspar, R.L. Binding of the La autoantigen to the $5^{\prime}$ untranslated region of a chimeric human translation elongation factor 1A reporter mRNA inhibits translation in vitro. Biochim. Biophys. Acta Gene Struct. Expr. 2001, 1521, 19-29. [CrossRef] 
39. Caldarola, S.; de Stefano, M.C.; Amaldi, F.; Loreni, F. Synthesis and function of ribosomal proteins-Fading models and new perspectives. FEBS J. 2009, 276, 3199-3210. [CrossRef]

40. Tcherkezian, J.; Cargnello, M.; Romeo, Y.; Huttlin, E.L.; Lavoie, G.; Gygi, S.P.; Roux, P.P. Proteomic analysis of cap-dependent translation identifies LARP1 as a key regulator of 5'TOP mRNA translation. Genes Dev. 2014, 28, 357-371. [CrossRef]

41. Lahr, R.; Mack, S.M.; Héroux, A.; Blagden, S.P.; Bousquet-Antonelli, C.; Deragon, J.-M.; Berman, A.J. The La-related protein 1-specific domain repurposes HEAT-like repeats to directly bind a $5^{\prime} \mathrm{TOP}$ sequence. Nucleic Acids Res. 2015, 43, 8077-8088. [CrossRef]

42. Lahr, R.; Fonseca, B.D.; Ciotti, G.E.; A Al-Ashtal, H.; Jia, J.-J.; Niklaus, M.R.; Blagden, S.P.; Alain, T.; Berman, A. La-related protein 1 (LARP1) binds the mRNA cap, blocking eIF4F assembly on TOP mRNAs. eLife 2017, 6. [CrossRef] [PubMed]

43. Blagden, S.P.; Gatt, M.K.; Archambault, V.; Lada, K.; Ichihara, K.; Lilley, K.S.; Inoue, Y.H.; Glover, D.M. Drosophila Larp associates with poly(A)-binding protein and is required for male fertility and syncytial embryo development. Dev. Biol. 2009, 334, 186-197. [CrossRef]

44. Burrows, C.; Latip, N.A.; Lam, S.-J.; Carpenter, L.; Sawicka, K.; Tzolovsky, G.; Gabra, H.; Bushell, M.; Glover, D.M.; Willis, A.E.; et al. The RNA binding protein Larp1 regulates cell division, apoptosis, and cell migration. Nucleic Acids Res. 2010, 38, 5542-5553. [CrossRef]

45. Xie, C.; Huang, L.; Xie, S.-B.; Xie, D.-Y.; Zhang, G.-L.; Wang, P.; Peng, L.; Gao, Z.-L. LARP1 predict the prognosis for early-stage and AFP-normal hepatocellular carcinoma. J. Transl. Med. 2013, 11, 272. [CrossRef] [PubMed]

46. Xu, Z.; Xu, J.; Lu, H.; Lin, B.; Cai, S.; Guo, J.; Zang, F.; Chen, R. LARP1 is regulated by the XIST/miR-374a axis and functions as an oncogene in non-small cell lung carcinoma. Oncol. Rep. 2017, 38, 3659-3667. [CrossRef] [PubMed]

47. Ye, L.; Lin, S.-T.; Mi, Y.-S.; Liu, Y.; Ma, Y.; Sun, H.-M.; Peng, Z.-H.; Fan, J.-W. Overexpression of LARP1 predicts poor prognosis of colorectal cancer and is expected to be a potential therapeutic target. Tumor Biol. 2016, 37, 14585-14594. [CrossRef] [PubMed]

48. Aoki, K.; Adachi, S.; Homoto, M.; Kusano, H.; Koike, K.; Natsume, T. LARP1 specifically recognizes the 3' terminus of poly(A) mRNA. FEBS Lett. 2013, 587, 2173-2178. [CrossRef] [PubMed]

49. Gentilella, A.; Morón-Duran, F.D.; Fuentes, P.; Rocha, G.; Riaño-Canalias, F.; Pelletier, J.; Ruiz, M.; Turón, G.; Castaño, J.; Tauler, A.; et al. Autogenous Control of 5'TOP mRNA Stability by 40 S Ribosomes. Mol. Cell 2017, 67, 55-70. [CrossRef]

50. Hong, S.; Freeberg, M.; Han, T.; Kamath, A.; Yao, Y.; Fukuda, T.; Suzuki, T.; Kim, J.K.; Inoki, K. LARP1 functions as a molecular switch for mTORC1-mediated translation of an essential class of mRNAs. eLife 2017, 6. [CrossRef]

51. Hsu, P.P.; Kang, S.A.; Rameseder, J.; Zhang, Y.; Ottina, K.A.; Lim, D.; Peterson, T.R.; Choi, Y.; Gray, N.S.; Yaffe, M.B.; et al. The mTOR-Regulated Phosphoproteome Reveals a Mechanism of mTORC1-Mediated Inhibition of Growth Factor Signaling. Science 2011, 332, 1317-1322. [CrossRef] [PubMed]

52. Yu, Y.; Yoon, S.-O.; Poulogiannis, G.; Yang, Q.; Ma, X.M.; Villén, J.; Kubica, N.; Hoffman, G.R.; Cantley, L.C.; Gygi, S.P.; et al. Phosphoproteomic Analysis Identifies Grb10 as an mTORC1 Substrate That Negatively Regulates Insulin Signaling. Science 2011, 332, 1322-1326. [CrossRef] [PubMed]

53. Kang, S.A.; Pacold, M.E.; Cervantes, C.L.; Lim, D.; Lou, H.J.; Ottina, K.; Gray, N.S.; Turk, B.E.; Yaffe, M.B.; Sabatini, D.M. mTORC1 Phosphorylation Sites Encode Their Sensitivity to Starvation and Rapamycin. Science 2013, 341, 1236566. [CrossRef] [PubMed]

54. Mura, M.; Hopkins, T.G.; Michael, T.; Abd-Latip, N.; Weir, J.; Aboagye, E.; Mauri, F.; Jameson, C.; Sturge, J.; Gabra, H.; et al. LARP1 post-transcriptionally regulates mTOR and contributes to cancer progression. Oncogene 2014, 34, 5025-5036. [CrossRef]

55. Quiocho, F.A.; Hu, G.; Gershon, P.D. Structural basis of mRNA cap recognition by proteins. Curr. Opin. Struct. Biol. 2000, 10, 78-86. [CrossRef]

56. Tomoo, K.; Shen, X.; Okabe, K.; Nozoe, Y.; Fukuhara, S.; Morino, S.; Sasaki, M.; Taniguchi, T.; Miyagawa, H.; Kitamura, K.; et al. Structural features of human initiation factor $4 \mathrm{E}$, studied by X-ray crystal analyses and molecular dynamics simulations. J. Mol. Biol. 2003, 328, 365-383. [CrossRef] 
57. Shama, S.; Avni, D.; Frederickson, R.M.; Sonenberg, N.; Meyuhas, O. Overexpression of Initiation Factor eIF-4E Does Not Relieve the Translational Repression of Ribosomal Protein mRNAs in Quiescent Cells. Gene Expr. 2018, 4, 241-252.

58. Al-Ashtal, H.A.; Rubottom, C.M.; Leeper, T.C.; Berman, A. The LARP1 La-Module recognizes both ends of TOP mRNAs. RNA Biol. 2019, 1-11. [CrossRef]

59. Huichalaf, C.; Schoser, B.; Schneider-Gold, C.; Jin, B.; Sarkar, P.; Timchenko, L.T. Reduction of the rate of protein translation in patients with myotonic dystrophy 2. J. Neurosci. 2009, 29, 9042-9049. [CrossRef]

60. Pellizzoni, L.; Lotti, F.; Rutjes, S.A.; Pierandrei-Amaldi, P. Involvement of the Xenopus laevis Ro60 autoantigen in the alternative interaction of La and CNBP proteins with the 5'UTR of L4 ribosomal protein mRNA. J. Mol. Biol. 1998, 281, 593-608. [CrossRef]

61. Liquori, C.L. Myotonic Dystrophy Type 2 Caused by a CCTG Expansion in Intron 1 of ZNF9. Science 2001, 293, 864-867. [CrossRef]

62. Schoser, B.; Timchenko, L.T. Myotonic Dystrophies 1 and 2: Complex Diseases with Complex Mechanisms. Curr. Genom. 2010, 11, 77-90. [CrossRef] [PubMed]

63. Wei, C.; Stock, L.; Schneider-Gold, C.; Sommer, C.; Timchenko, N.A.; Timchenko, L. Reduction of Cellular Nucleic Acid Binding Protein Encoded by a Myotonic Dystrophy Type 2 Gene Causes Muscle Atrophy. Mol. Cell. Biol. 2018, 38, mcb-00649. [CrossRef] [PubMed]

64. Pelletier, R.; Hamel, F.; Beaulieu, D.; Patry, L.; Haineault, C.; Tarnopolsky, M.; Schoser, B.; Puymirat, J. Absence of a differentiation defect in muscle satellite cells from DM2 patients. Neurobiol. Dis. 2009, 36, 181-190. [CrossRef] [PubMed]

65. Schneider-Gold, C.; Timchenko, L.T. CCUG Repeats Reduce the Rate of Global Protein Synthesis in Myotonic Dystrophy Type 2. Rev. Neurosci. 2010, 21, 19-28. [CrossRef]

66. Benhalevy, D.; Gupta, S.K.; Danan, C.H.; Ghosal, S.; Sun, H.-W.; Kazemier, H.G.; Paeschke, K.; Hafner, M.; Juranek, S.A. The Human CCHC-type Zinc Finger Nucleic Acid-Binding Protein Binds G-Rich Elements in Target mRNA Coding Sequences and Promotes Translation. Cell Rep. 2017, 18, 2979-2990. [CrossRef]

67. Fay, M.M.; Lyons, S.M.; Ivanov, P. RNA G-Quadruplexes in Biology: Principles and Molecular Mechanisms. J. Mol. Biol. 2017, 429, 2127-2147. [CrossRef]

68. Sauer, M.; Juranek, S.A.; Marks, J.; de Magis, A.; Kazemier, H.G.; Hilbig, D.; Benhalevy, D.; Wang, X.; Hafner, M.; Paeschke, K. DHX36 prevents the accumulation of translationally inactive mRNAs with G4-structures in untranslated regions. Nat. Commun. 2019, 10, 2421. [CrossRef]

69. Ghosal, G.; Muniyappa, K. Hoogsteen base-pairing revisited: Resolving a role in normal biological processes and human diseases. Biochem. Biophys. Res. Commun. 2006, 343, 1-7. [CrossRef]

70. Dember, L.M.; Kim, N.D.; Liu, K.-Q.; Anderson, P. Individual RNA Recognition Motifs of TIA-1 and TIAR Have Different RNA Binding Specificities. J. Biol. Chem. 1996, 271, 2783-2788. [CrossRef]

71. Gueydan, C.; Droogmans, L.; Chalon, P.; Huez, G.; Caput, D.; Kruys, V. Identification of TIAR as a Protein Binding to the Translational Regulatory AU-rich Element of Tumor Necrosis Factor $\alpha$ mRNA. J. Biol. Chem. 1999, 274, 2322-2326. [CrossRef]

72. de Silanes, I.L.; Galbán, S.; Martindale, J.L.; Yang, X.; Mazan-Mamczarz, K.; Indig, F.E.; Falco, G.; Zhan, M.; Gorospe, M. Identification and Functional Outcome of mRNAs Associated with RNA-Binding Protein TIA-1. Mol. Cell. Biol. 2005, 25, 9520-9531. [CrossRef]

73. Mazan-Mamczarz, K.; Lal, A.; Martindale, J.L.; Kawai, T.; Gorospe, M. Translational Repression by RNA-Binding Protein TIAR. Mol. Cell. Biol. 2006, 26, 2716-2727. [CrossRef]

74. Piecyk, M.; Wax, S.; Beck, A.R.; Kedersha, N.; Gupta, M.; Maritim, B.; Chen, S.; Gueydan, C.; Kruys, V.; Streuli, M.; et al. TIA-1 is a translational silencer that selectively regulates the expression of TNF- $\alpha$. EMBO J. 2000, 19, 4154-4163. [CrossRef] [PubMed]

75. Kedersha, N.; Chen, S.; Gilks, N.; Li, W.; Miller, I.J.; Stahl, J.; Anderson, P. Evidence That Ternary Complex (eIF2-GTP-tRNAiMet)-Deficient Preinitiation Complexes Are Core Constituents of Mammalian Stress Granules. Mol. Biol. Cell 2002, 13, 195-210. [CrossRef] [PubMed]

76. Aulas, A.; Fay, M.M.; Lyons, S.M.; Achorn, C.A.; Kedersha, N.; Anderson, P.; Ivanov, P. Stress-specific differences in assembly and composition of stress granules and related foci. J. Cell Sci. 2017, 130, 927-937. [CrossRef] 
77. Kedersha, N.; Stoecklin, G.; Ayodele, M.; Yacono, P.; Lykke-Andersen, J.; Fritzler, M.J.; Scheuner, D.; Kaufman, R.J.; Golan, D.E.; Anderson, P. Stress granules and processing bodies are dynamically linked sites of mRNP remodeling. J. Cell Biol. 2005, 169, 871-884. [CrossRef] [PubMed]

78. Markmiller, S.; Soltanieh, S.; Server, K.L.; Mak, R.; Jin, W.; Fang, M.Y.; Luo, E.-C.; Krach, F.; Yang, D.; Sen, A.; et al. Context-Dependent and Disease-Specific Diversity in Protein Interactions within Stress Granules. Cell 2018, 172, 590-604. [CrossRef]

79. Kedersha, N.; Cho, M.R.; Li, W.; Yacono, P.W.; Chen, S.; Gilks, N.; Golan, D.E.; Anderson, P. Dynamic Shuttling of Tia-1 Accompanies the Recruitment of mRNA to Mammalian Stress Granules. J. Cell Biol. 2000, 151, 1257-1268. [CrossRef]

80. Damgaard, C.K.; Lykke-Andersen, J. Translational coregulation of 5'TOP mRNAs by TIA-1 and TIAR. Genes Dev. 2011, 25, 2057-2068. [CrossRef]

81. Kim, H.S.; Kuwano, Y.; Zhan, M.; Pullmann, R.; Mazan-Mamczarz, K.; Li, H.; Kedersha, N.; Anderson, P.; Wilce, M.C.J.; Gorospe, M.; et al. Elucidation of a C-Rich Signature Motif in Target mRNAs of RNA-Binding Protein TIAR. Mol. Cell. Biol. 2007, 27, 6806-6817. [CrossRef] [PubMed]

82. Wagner, B.J.; de Maria, C.T.; Sun, Y.; Wilson, G.; Brewer, G. Structure and Genomic Organization of the Human AUF1 Gene: Alternative Pre-mRNA Splicing Generates Four Protein Isoforms. Genomics 1998, 48, 195-202. [CrossRef] [PubMed]

83. de Maria, C.T.; Sun, Y.; Long, L.; Wagner, B.J.; Brewer, G. Structural Determinants in AUF1 Required for High Affinity Binding to A + U-rich Elements. J. Biol. Chem. 1997, 272, 27635-27643. [CrossRef] [PubMed]

84. Wilson, G.; Sun, Y.; Lu, H.; Brewer, G. Assembly of AUF1 Oligomers on U-rich RNA Targets by Sequential Dimer Association. J. Biol. Chem. 1999, 274, 33374-33381. [CrossRef]

85. Meyer, A.; Golbik, R.P.; Sänger, L.; Schmidt, T.; Behrens, S.-E.; Friedrich, S. The RGG/RG motif of AUF1 isoform p45 is a key modulator of the protein's RNA chaperone and RNA annealing activities. RNA Biol. 2019, 16, 960-971. [CrossRef]

86. Zucconi, B.E.; Ballin, J.D.; Brewer, B.Y.; Ross, C.R.; Huang, J.; Toth, E.A.; Wilson, G. Alternatively Expressed Domains of AU-rich Element RNA-binding Protein 1 (AUF1) Regulate RNA-binding Affinity, RNA-induced Protein Oligomerization, and the Local Conformation of Bound RNA Ligands. J. Biol. Chem. 2010, 285, 39127-39139. [CrossRef]

87. White, E.J.; Brewer, G.; Wilson, G. Post-transcriptional control of gene expression by AUF1: Mechanisms, physiological targets, and regulation. Biochim. Biophys. Acta Bioenerg. 2012, 1829, 680-688. [CrossRef]

88. Hendrayani, S.-F.; Al-Harbi, B.; Al-Ansari, M.; Silva, G.; Aboussekhra, A. The inflammatory/cancer-related IL-6/STAT3/NF- KB positive feedback loop includes AUF1 and maintains the active state of breast myofibroblasts. Oncotarget 2016, 7, 41974-41985. [CrossRef]

89. Hendrayani, S.-F.; Al-Khalaf, H.H.; Aboussekhra, A. The Cytokine IL-6 Reactivates Breast Stromal Fibroblasts through Transcription Factor STAT3-dependent Up-regulation of the RNA-binding Protein AUF1. J. Biol. Chem. 2014, 289, 30962-30976. [CrossRef]

90. Al-Khalaf, H.H.; Aboussekhra, A. AUF1 positively controls angiogenesis through mRNA stabilization-dependent up-regulation of HIF-1 $\alpha$ and VEGF-A in human osteosarcoma. Oncotarget 2019, 10, 4868-4879. [CrossRef]

91. Liao, B.; Hu, Y.; Brewer, G. Competitive binding of AUF1 and TIAR to MYC mRNA controls its translation. Nat. Struct. Mol. Biol. 2007, 14, 511-518. [CrossRef]

92. Yoon, J.-H.; de, S.; Srikantan, S.; Abdelmohsen, K.; Grammatikakis, I.; Kim, J.; Kim, K.M.; Noh, J.H.; White, E.J.F.; Martindale, J.L.; et al. PAR-CLIP analysis uncovers AUF1 impact on target RNA fate and genome integrity. Nat. Commun. 2014, 5, 5248. [CrossRef] [PubMed]

93. Kakegawa, T.; Ohuchi, N.; Hayakawa, A.; Hirata, S.; Matsuda, M.; Kogure, K.; Kobayashi, H.; Inoue, A.; Kaspar, R.L. Identification of AUF1 as a rapamycin-responsive binding protein to the $5^{\prime}$-terminal oligopyrimidine element of mRNAs. Arch. Biochem. Biophys. 2007, 465, 274-281. [CrossRef] [PubMed]

94. Hopkins, T.G.; Mura, M.; Al-Ashtal, H.A.; Lahr, R.M.; Abd-Latip, N.; Sweeney, K.; Lu, H.; Weir, J.; El-Bahrawy, M.; Steel, J.H.; et al. The RNA-binding protein LARP1 is a post-transcriptional regulator of survival and tumorigenesis in ovarian cancer. Nucleic Acids Res. 2015, 44, 1227-1246. [CrossRef] [PubMed] 
95. Rojas, M.; Farr, G.W.; Fernandez, C.F.; Lauden, L.; McCormack, J.C.; Wolin, S.L. Yeast Gis2 and Its Human Ortholog CNBP Are Novel Components of Stress-Induced RNP Granules. PLoS ONE 2012, 7, e52824. [CrossRef] [PubMed]

96. Wu, S.; Lin, L.; Zhao, W.; Li, X.; Wang, Y.; Si, X.; Wang, T.; Wu, H.; Zhai, X.; Zhong, X.; et al. AUF1 is recruited to the stress granules induced by coxsackievirus B3. Virus Res. 2014, 192, 52-61. [CrossRef] 